\title{
Implementing falls prevention research into policy and practice: an overview of a new National Health and Medical Research Council Partnership Grant
}

\author{
Stephen R. Lord ${ }^{\mathrm{A}, \mathrm{C}}$, Kim Delbaere ${ }^{\mathrm{A}}$, \\ Anne Tiedemann ${ }^{\mathrm{B}}$, Stuart T. Smith ${ }^{\mathrm{A}}$ \\ and Daina L. Sturnieks ${ }^{\mathrm{A}}$ \\ ${ }^{\mathrm{A}}$ Falls and Balance Research Group, Neuroscience Research \\ Australia, The University of New South Wales \\ ${ }^{\mathrm{B}}$ The George Institute for International Health \\ ${ }^{\mathrm{C}}$ Corresponding author. Email: s.lord@neura.edu.au
}

\begin{abstract}
Preventing falls and fall-related injuries among older people is an urgent public health challenge. This paper provides an overview of the background to and research planned for a 5-year National Health and Medical Research Council Partnership Grant on implementing falls prevention research findings into policy and practice. This program represents a partnership between key Australian falls prevention researchers, policy makers and information technology companies which aims to: (1) fill gaps in evidence relating to the prevention of falls in older people, involving new research studies of risk factor assessment and interventions for falls prevention; (2) translate evidence into policy and practice, examining the usefulness of new risk-identification tools in clinical practice; and (3) disseminate evidence to health professionals working with older people, via presentations, new evidencebased guidelines, improved resources and learning tools, to improve the workforce capacity to prevent falls and associated injuries in the future.
\end{abstract}

Falls in older Australians are a significant public health issue. With at least one-third of people aged 65 years and over falling one or more times every year, the health burden within the community associated with falls is enormous. Falls are the leading cause of injury-related death and hospitalisation in persons aged 65 years and over. Furthermore, falls can result in permanent disability, restriction of activity, loss of confidence and fear of falling, all of which reduce quality of life and independence. It has been projected that by 2051 the total annual Australian health bill for fall-related injury will increase almost threefold to $\$ 1.4$ billion. ${ }^{1}$ The ageing of Australia's population - estimates suggest that by 2021 more than 5 million Australians will be aged 65 years and over - means that this problem is increasing. ${ }^{1}$ Developing and implementing strategies to prevent falls and fall-related injuries among older people is therefore an urgent public health challenge and one of the key priority areas previously identified by Commonwealth and state health departments.

This paper describes a new National Health and Medical Research Council Partnership research program. This grant scheme encourages collaboration between researchers and partner organisations to identify research needs, conduct research, and promote the use of research findings to influence the design and evaluation of health and health care policy and practice. The current program brings together researchers, policy makers, educational institutions and the information technology industry with three specific themes:

- conducting research where gaps in evidence have been identified

- identifying strategies for translating evidence into practice

- disseminating evidence to inform policy and practice.

The program has the potential to provide health professionals with the knowledge and resources to better identify people at risk of falling and to implement strategies for the prevention of falls and associated injuries in this group.

\section{Participants}

This program is directed by Professor Stephen Lord (Neuroscience Research Australia (NeuRA)) and has seven other Chief Investigators: Professor Ian Cameron (Rehabilitation Studies Unit, University of Sydney), Associate Professor Jacqueline Close (Prince of Wales Hospital and NeuRA), Dr Kim Delbaere (NeuRA), Dr Catherine Sherrington (The George Institute for International 
Health), Dr Stuart Smith (NeuRA), Dr Daina Sturnieks (NeuRA) and Dr Anne Tiedemann (The George Institute for International Health).

The co-funding organisations are the New South Wales (NSW) Department of Health, the Australian Commission on Safety and Quality in Health Care, Kinetics Foundation, NeuRA and the University of NSW.

There are four Associate Investigators who bring clinical and research expertise from a broad range of backgrounds including medical technology, emergency medicine, public health and health promotion. They are: Professor Caroline Finch (Monash Injury Research Institute), Dr Roslyn Poulos (University of NSW), Ms Elizabeth King (NSW Health) and Dr Paul Middleton (Ambulance Service of NSW).

\section{Research projects}

There are now encouraging findings from well planned and executed studies which indicate that many falls are preventable. $^{2,3}$ The research projects within this partnership will focus on four current gaps in the literature.

\section{Early identification of older people at risk for falls living within the community}

Patients presenting to emergency departments and/or the Ambulance Service of NSW represent an easily identifiable high-risk population. The evidence to date suggests that these people benefit from a multi-disciplinary falls risk assessment ${ }^{4,5}$ to guide them towards targeted multifactorial interventions. ${ }^{4}$ This project will develop screening tools for use in emergency departments and by the Ambulance Service of NSW, as well as associated referral protocols to allow for the identification of those most at risk of falls and to allow a more cost-effective approach to intervention and prevention.

\section{Including fear of falling in falls risk assessment tools}

There is now strong evidence that the inclusion of psychological and cognitive factors will potentially improve the accuracy of established falls risk assessment tools in the prediction of future falls. ${ }^{6}$ This project will develop and validate clinical diagnostic tools for screening older people for excessive fear of falling, risk taking behaviour and physical activity levels. Additionally, the utility of these tools for evaluating treatment effects will be evaluated in two experimental studies. Results of these experiments will be incorporated into new proposals to external funding bodies, aiming to develop accessible, individually-tailored cognitive-behavioural treatment methods to reduce fear of falling.

\section{Telehealth technology for cost-effective delivery of quality health care}

Telehealth technology, which combines digital data acquisition and communication technologies to monitor health status in the home, is gaining attention as a promising strategy for acquiring accurate and reliable data of health markers. ${ }^{7}$ This project will explore the use of four different telehealth technologies in a falls-related context. It will: (1) validate a device for measuring and monitoring balance and gait in older people's homes; (2) develop prototypes of mobile internet devices to enhance independent living; (3) develop and validate activity monitors and automated fall detection software applications for the iPod Touch; and (4) develop age-appropriate Nintendo Wii-style 'exergames' for in-home exercise.

\section{Predictors of adherence to prescribed exercise interventions}

Current best evidence indicates that exercise plays a crucial role in the widespread prevention of falls and disability. ${ }^{2,8,9}$ While randomised control trials have been successful, adherence with exercise interventions is often disappointing, suggesting some reluctance on the part of older adults to take part in such programs. This project aims to establish predictors of adherence to home-based exercise programs in people recently discharged from hospital. This study has the potential to enhance clinical and public health practice by enabling exercise programs to be designed with these factors in mind and strategies for maximising adherence to be developed.

\section{Translation projects}

The translation of research findings into sustainable improvements in clinical practice and patient outcomes remains a substantial obstacle to improving the quality of health care. As indicated above, in one of the research projects we will develop falls risk screening tools for use in ambulance and emergency department settings. In addition, with NSW Health funding we have recently developed a falls risk screening tool for rehabilitation units. ${ }^{10} \mathrm{As}$ part of this partnership project we will undertake further validation of these tools and assess their usefulness in daily clinical practice. Large implementation studies will investigate whether these falls risk screening tools can be incorporated into routine practice by the Ambulance Service of NSW, emergency department staff and rehabilitation units. These tools have the potential to prevent falls by providing a valid yet quick indication of an individual's risk of falling so that preventive strategies can be put in place.

\section{Dissemination projects}

A key aspect of the program is the dissemination of the results of research to clinicians from a range of disciplines, health promotion practitioners, policy officers and members of the community. Researchers are increasingly recognising the need to take steps to facilitate the translation of research findings into practice. Five different strategies will be employed as part of this project to 
actively disseminate available evidence-based research findings.

\section{Development of evidence-based guidelines}

Evidence-based guidelines are crucial to provide health practitioners with relevant and up-to-date information about falls and falls injuries in older people and appropriate treatment options. By improving the knowledge, and therefore, practice of clinicians, the guidelines can also improve the health outcomes for older people. This project will assist the Australian Commission on Safety and Quality in Health Care to review the current Falls Prevention Guidelines (2009-2012), ${ }^{11}$ taking into account National Health and Medical Research Council Clinical Practice Guidelines. ${ }^{12}$

\section{Enhancement of the Australian and New Zealand Falls Prevention Society}

The Australian and New Zealand Falls Prevention Society (ANZFPS) was officially launched at the 2008 Australian Falls Prevention Conference. The objectives of the ANZFPS are to organise biennial conferences and to promote the broad discipline of falls prevention research. ${ }^{13}$ As part of this project, the ANZFPS will be enhanced so that it provides a nationwide one-stop source for the provision of falls prevention information and resources for researchers, clinicians and older people. This will include the development of an internet-based clinical assessment and intervention tool for use as an educational resource and guide for health practitioners.

\section{Policy round tables}

As part of a recent National Health and Medical Research Council Population Health Capacity Building Grant, a Falls Translation Task Group was trialed as one mechanism to improve the dissemination and uptake of falls research into policy and practice, and to foster the development of policy-appropriate research. ${ }^{14,15}$ This project will establish and maintain a National Falls Translation Task Group with broad membership comprising falls researchers, policy makers from state, territory and Commonwealth Departments of Health, health professionals including allied health practitioners and clinicians, and representatives from non-government sectors such as the aged care and fitness industries. The National Falls Translation Task Group will provide the infrastructure necessary to actively promote dialogue between falls researchers, policy makers and stakeholders. This will encourage a policy-sensitive research agenda and enhance capacity for evidence-informed policy and practice in falls management.

\section{Presenting falls prevention evidence to clinical groups}

One of the major barriers in the implementation of falls prevention research into clinical practice is communicating the current evidence to medical practitioners involved in the routine and specialist care of older people. The chief investigators of this project will present up-to-date evidence-based falls research in symposia, breakfast sessions and proffered presentations to general practitioners, medical specialists and optometrists at their annual scientific meetings.

\section{Curriculum development}

Allied health professionals, including physiotherapists and occupational therapists, have a crucial role to play in falls prevention. These professionals can prescribe appropriate exercise for people with specific needs, such as frailty and co-morbidities. Curricula for allied health professionals needs to be scoped and modified accordingly to build a workforce that is equipped to provide necessary services to prevent falls in older people. ${ }^{16,17}$ This project will involve researchers working with university departments to assess current physiotherapy and occupational therapy curricula in relation to the provision of exercise interventions for falls prevention. We will develop and implement new curricula appropriate to these needs and evaluate outcomes in terms of improvements in knowledge and skills.

\section{Conclusion}

This project represents a partnership between Australian falls prevention researchers, policy makers and information technology companies. The proposed projects comprise: new studies aimed at filling the gaps in falls prevention research (i.e. refining and developing falls assessments and intervention strategies that can be readily applied in the community); translation and implementation research which will determine how best to incorporate research evidence into routine clinical practice; and dissemination projects aimed at ensuring policy makers and clinicians can be informed of research findings, in order to improve the workforce capacity to prevent falls and associated injuries in the future.

\section{References}

1. Moller J. Projected costs of fall related injury to older persons due to demographic change in Australia. Canberra: Commonwealth Department of Health and Ageing; 2003.

2. Gillespie L, Robertson M, Gillespie W, Lamb S, Gates S, Cumming $\mathrm{R}$ et al. Interventions for preventing falls in older people living in the community. Cochrane Database Syst Rev 2009; (2): CD007146.

3. Cameron ID, Murray GR, Gillespie LD, Robertson MC, Hill KD, Cumming RG et al. Interventions for preventing falls in older people in nursing care facilities and hospitals. Cochrane Database Syst Rev 2010; 1: CD005465.

4. Close J, Ellis M, Hooper R, Glucksman E, Jackson S, Swift C. Prevention of falls in the elderly trial (PROFET): a randomised controlled trial. Lancet 1999; 353(9147): 93-7. doi:10.1016/ S0140-6736(98)06119-4

5. Davison J, Bond J, Dawson P, Steen IN, Kenny RA. Patients with recurrent falls attending Accident \& Emergency benefit from 
multifactorial intervention - a randomised controlled trial. Age Ageing 2005; 34(2): 162-8. doi:10.1093/ageing/afi053

6. Delbaere K, Close JCT, Brodaty H, Sachdev P, Lord SR. Determinants of disparities between perceived and physiological risk of falling among elderly people: cohort study. $B M J 2010$; 341: c4165.

7. Pare G, Jaana M, Sicotte C. Systematic review of home telemonitoring for chronic diseases: the evidence base. J Am Med Inform Assoc 2007; 14(3): 269-77. doi:10.1197/ jamia.M2270

8. Pahor M, Blair SN, Espeland M, Fielding R, Gill TM, Guralnik $\mathrm{JM}$ et al. Effects of a physical activity intervention on measures of physical performance: results of the lifestyle interventions and independence for Elders Pilot (LIFE-P) study. J Gerontol A Biol Sci Med Sci 2006; 61(11): 1157-65.

9. Sherrington C, Whitney JC, Lord SR, Herbert RD, Cumming RG, Close JCT. Effective exercise for the prevention of falls: a systematic review and meta-analysis. J Am Geriatr Soc 2008; 56(12): 2234-43. doi:10.1111/j.1532-5415.2008.02014.x

10. Sherrington C, Lord SR, Close JCT, Barraclough E, Taylor M, O'Rourke S et al. Development of a tool for prediction of falls in rehabilitation settings (Predict_FIRST): a prospective cohort study. J Rehabil Med 2010; 42(5): 482-8. doi:10.2340/ 16501977-0550

11. Falls Prevention Guidelines 2009-2012. Available from: http:// www.safetyandquality.gov.au/internet/safety/publishing.nsf/ Content/FallsGuidelines (Cited 10 March 2011.)
12. National Health and Medical Research Council. How to review the evidence: Systematic identification and review of scientific literature (2000). Available from: http://www.nhmrc.gov.au/ publications/synopses/cp65syn.htm (Cited 10 March 2011.)

13. Australian and New Zealand Falls Prevention Society [homepage on the internet]. Available from: http://www.anzfallsprevention.org/ (Cited 17 March 2011.)

14. Poulos RG, Zwi AB. Building capacity in injury research transfer. N S W Public Health Bull 2005; 16(11-12): 185-6.

15. Poulos RG, Zwi AB, Lord SR. Towards enhancing national capacity for evidence informed policy and practice in falls management: a role for a 'Translation Task Group'? Aust New Zealand Health Policy 2007; 4: 6. doi:10.1186/ 1743-8462-4-6

16. Pascoe DA, Finch CF, Sturnieks DL, Lord SR, Close JCT, Tiedemann A et al, editors. Knowledge outcomes of a university based falls prevention education program. Australian and New Zealand Falls Prevention Society Conference. Melbourne, Australia; 2008.

17. Sturnieks DL, Finch CF, Close JCT, Tiedemann A, Lord SR, Pascoe DA. Exercise for falls prevention in older people: assessing the knowledge of exercise science students. $\mathrm{J} \mathrm{Sci}$ Med Sport 2010; 13(1): 59-64. doi:10.1016/j.jsams.2008.11.005

\section{NSW PUBLIC HEALTH}

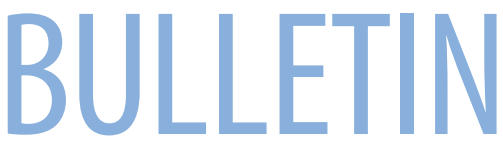

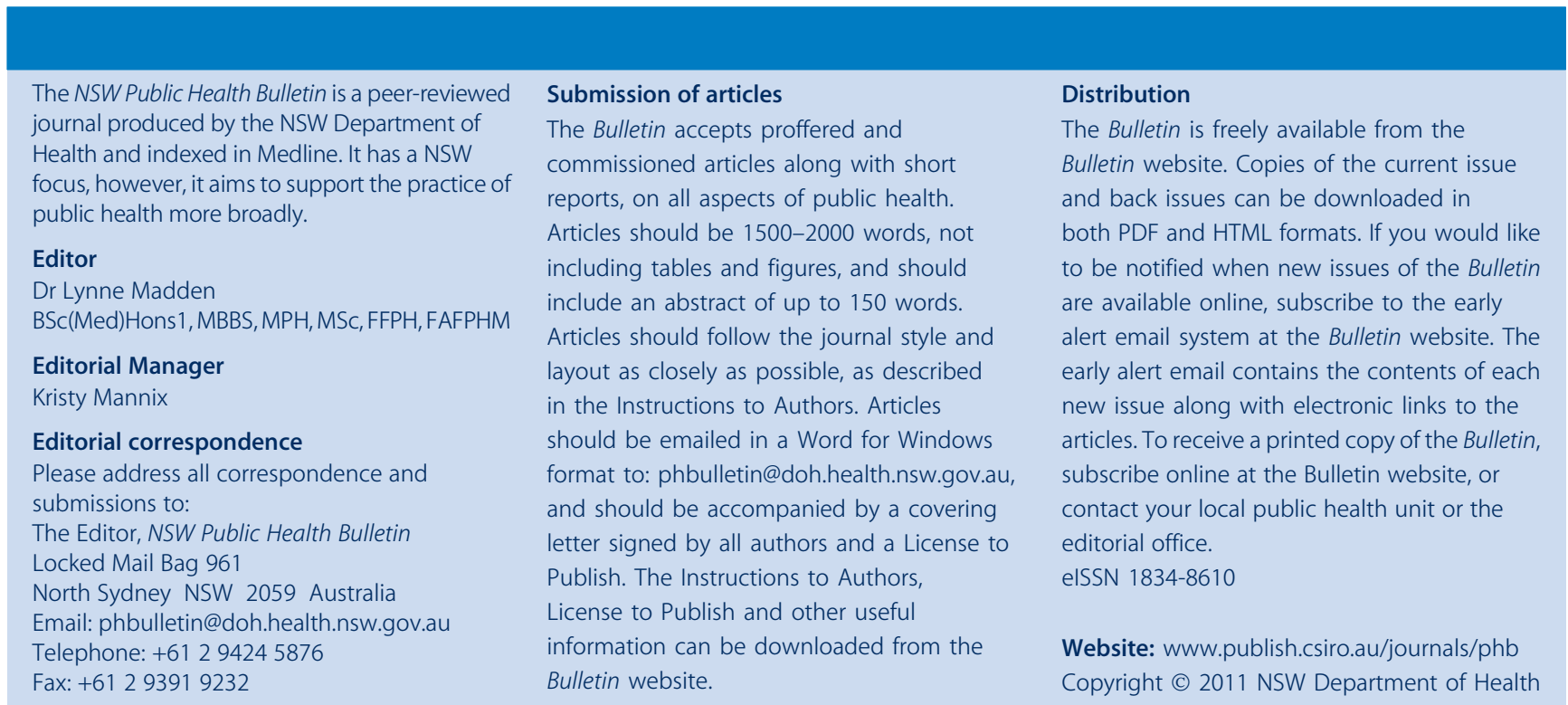

